\title{
Acquired Brain Injury
}

\section{The numbers behind the hidden disability}

A report by Headway - the brain injury association, with foreword by Professor Alan Tennant

May 2015

\section{brain tumour hydrocephalus}

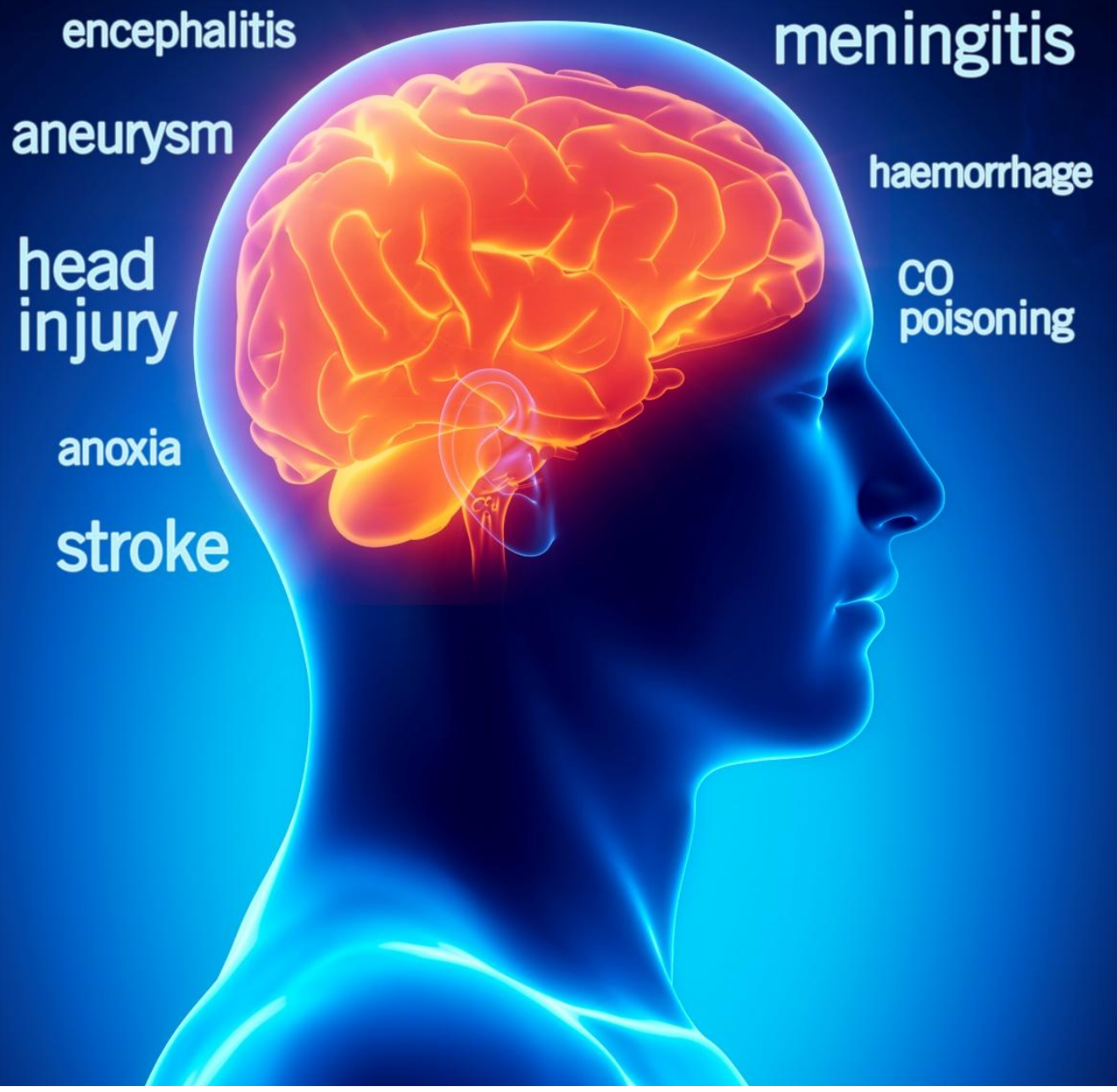




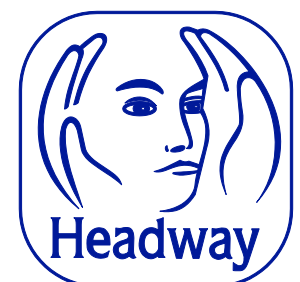

the brain injury association

\section{Key findings}

- There were 348,934 UK admissions to hospital with acquired brain injury in 2013-14. That is 566 admissions per 100,000 of the population.

- $A B I$ admissions in the UK have increased by $10 \%$ since $2005-6$.

- There were approximately $956 \mathrm{ABI}$ admissions per day to UK hospitals in 2013-14 - or one every 90 seconds.

- In 2013-14, there were $\mathbf{1 6 2 , 5 4 4}$ admissions for head injury. That equates to 445 every day, or one every three minutes.

- Men are 1.6 times more likely than women to be admitted for head injury. However, female head injury admissions have risen $24 \%$ since $2005-6$.

- In 2013-14, there were 130,551 UK admissions for stroke. That is an increase of $9 \%$ since $2005-6$ and equates to one every four minutes.

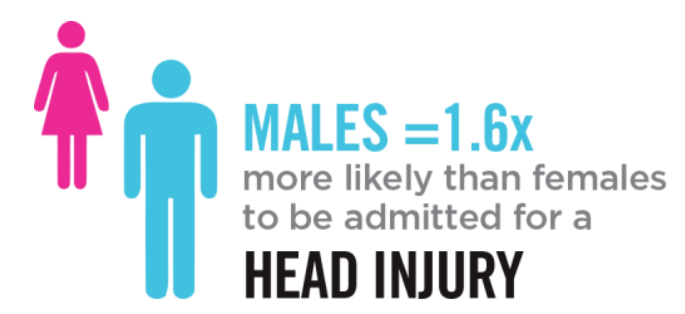

Notes:

- Years refer to financial years (1 April - 31 March)

- Comparison to 2005-6 data is due to information for Scotland only currently available from that year. Therefore, data for the entire UK is presented from that time. Data for England, Northern Ireland and Wales are available from 200001 , so combined data for those countries are presented separately.

- Many people die of stroke before admission to hospital so the actual number of strokes suffered is higher.

- $\quad$ Figures for Scotland are based on TBI (head injury) and stroke only. Statistics for other conditions were not available. Therefore, statistics shown for all $\mathrm{ABI}$ admissions and condition-specific admissions such as brain tumour will actually be higher than stated. 


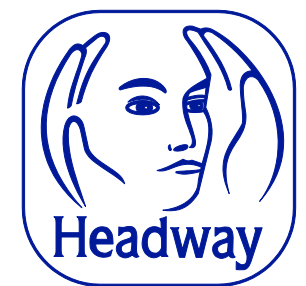

the brain injury association

\section{AGQUIRED \\ BRAN INJURY

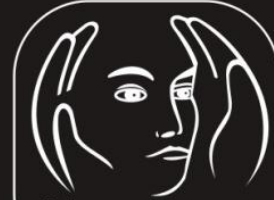 \\ Headway \\ the brain injury association}

\section{3-2014 STATISTICS BASED ON UK ADMISSIONS}
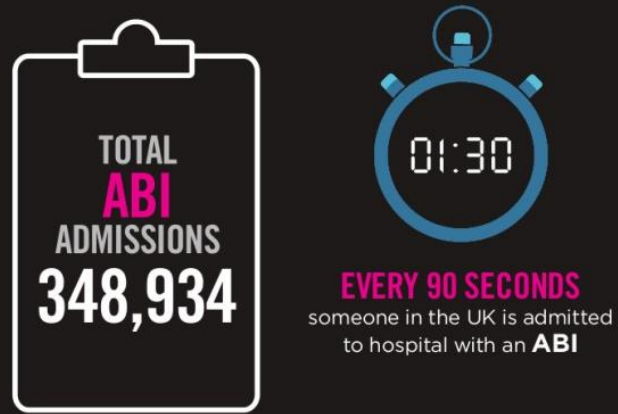

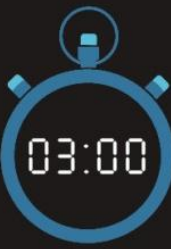

EVERY 3 MINUTES

someone in the UK is admitted to hospital with a HEAD INJURY

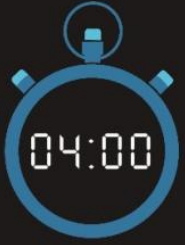

EVERY 4 MINUTES someone in the UK is admitted to hospital with a STROKE
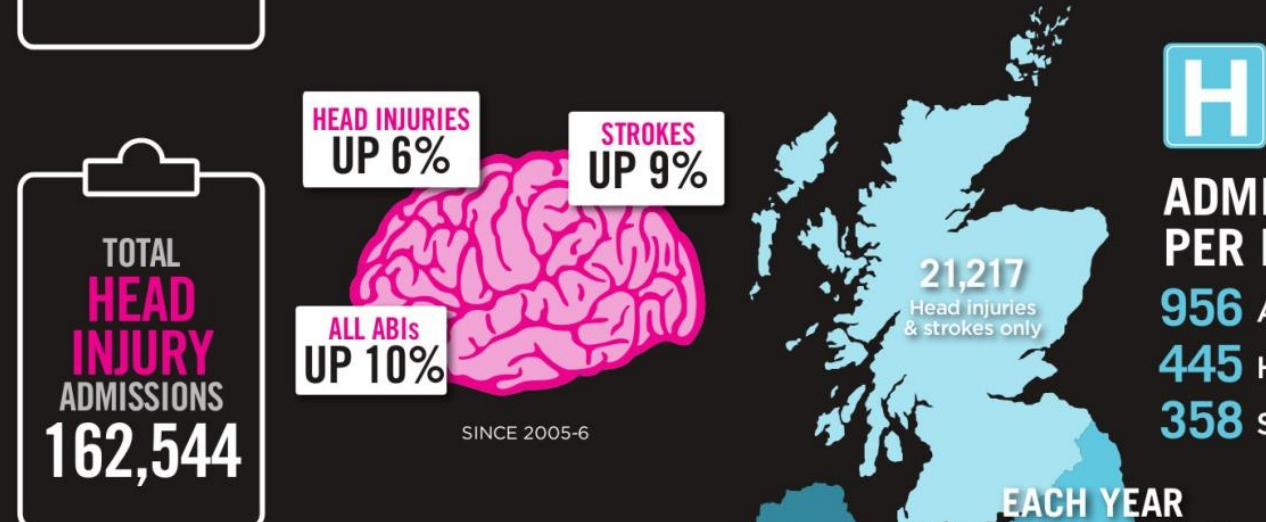

SINCE 2005-6

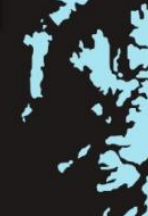

\section{ADMISSIONS} PER DAY 956 All ABls 445 Head injuries 358 strokes
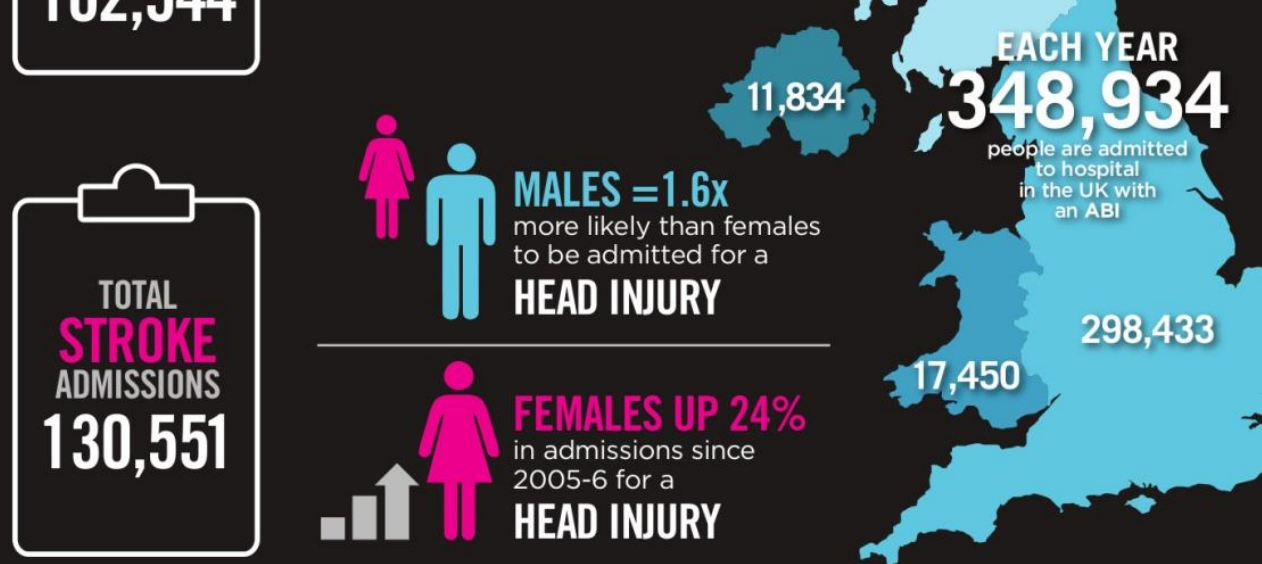
will be left with a long-term disability so ABI is used as short-hand for 'ABl-related diagnosis'. Admissions do not equate to individuals as one person can have For further information about brain injury or to access support:

Visit www.headway.org.uk Call 08088002244 Email helpline@headway.org.uk 


\section{Acquired Brain Injury}

\section{The numbers behind the hidden disability}

\section{Foreword}

For those of us who have worked in the field of brain injury epidemiology and rehabilitation provision, the need for accurate and up-to-date statistics to assist with service planning is well recognised. Consequently I have been delighted to consult with Headway on its work in this area and am very happy to support the release of these comprehensive new figures.

It is almost twenty years since colleagues and I published the studies The long-term outcome of head injury: Implications for service planning, and the Prevalence of selfreported stroke in a population in Northern England, and ten years since I published a Department of Health-funded study entitled Admission to hospital following head injury in England: Incidence and socio-economic association. The results confirmed that acquired brain injury is very common and constitutes a major public health concern.

The 2005 paper was used to inform the National Service Framework (NSF) for Long Term Conditions. The NSF was launched in 2005 with the aim, in a ten-year period, of improving services for people with neurological conditions and those who care for them. A decade on, the framework has expired having apparently failed to make significant changes to health and social care for people with those conditions.

It seems particularly timely, therefore, that Headway's detailed ABI admission statistics are released now, providing an up-to-date picture of the scale of the problem. There is no perfect way to quantify the number of people sustaining longterm disabilities as a result of brain injuries and the use of ICD-10 diagnosis codes to identify hospital admissions alone does not necessarily indicate this. However, Headway's work does provide the clearest picture to date of the pool of people who require support, from short-term advice and information, to long-term inpatient rehabilitation. It also provides up-to-date evidence with which to approach commissioners, and to request funding for rehabilitation and support services in areas of the greatest need.

I sincerely hope that this excellent research receives the attention it warrants in order to contribute to an improvement in future service provision.

\section{Professor Alan Tennant}

Emeritus Professor of Rehabilitation Studies, University of Leeds, and author of several articles on brain injury epidemiology 


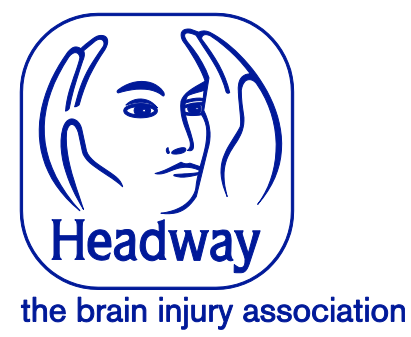

\section{Questions and answers}

\section{What do you mean by Acquired Brain Injury?}

Acquired brain injury $(A B I)$ is an umbrella term for any injury to the brain sustained since birth, excluding neurodegenerative conditions such as multiple sclerosis and

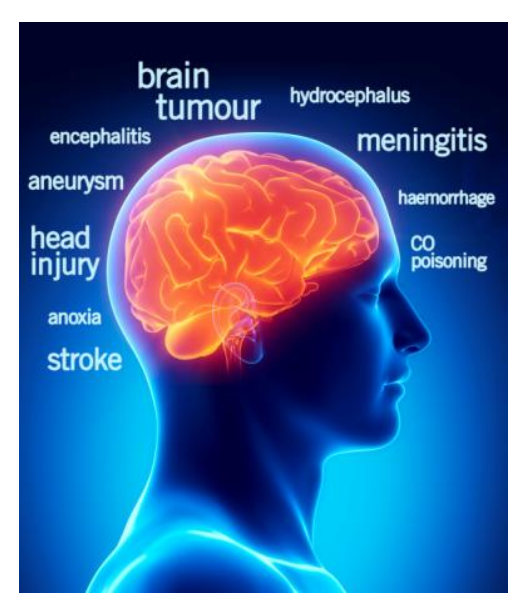
motor neurone disease. By far the most common forms of $\mathrm{ABI}$ are traumatic brain injury ( $\mathrm{TBI}$; otherwise referred to as head injury) and stroke. Other causes include brain tumour, meningitis, aneurysm, haemorrhage, encephalitis, anoxia, and other conditions.

The brain controls everything we do and brain injury can affect every aspect of who we are. The physical, cognitive, emotional and behavioural effects of $A B I$ can have devastating consequences for individuals and their families.

For further information about the effects of brain injury, click here.

\section{How have these statistics been collated?}

Using hospital admission numbers, Headway has compiled the first dataset on ABIrelated hospital admissions in the UK.

The figures presented here have been obtained using the Hospital Episode Statistics (HES) system in England and its equivalents elsewhere in the UK. These systemically record all hospital admissions according to diagnosis by International Classification of Disease Version 10 (ICD-10) code. The admission figures presented here are for primary diagnosis (the main condition required for treatment on admission).

The head injury figures are for non-superficial injuries, therefore increasing the likelihood that the majority of those represented in these figures will require some degree of information, support or rehabilitation on either a short or long-term basis. Standardised codes have been used for stroke, while codes for other ABI-related conditions have been collected by searching the ICD-10 code database and categorised according to condition.

Data for Scotland are only currently available for head injuries and stroke. Data for the entire UK, therefore, do not include other ABI related conditions in Scotland.

Further explanation on the way the figures were collated can be found here. 


\section{Why do the statistics only date back to 2005-06?}

As data for Scotland are currently available from 2005-06, statistics for the entire UK are presented from that time. Data for England, Northern Ireland and Wales are available from 2000-01, so combined data for these countries are presented separately.

\section{Do these statistics represent the number of people living with the effects of brain injury?}

The statistics presented here do not answer the question of prevalence (number of people living with disabilities at any given time).

Admission to hospital for an ABI-related diagnosis does not necessarily mean a patient will be left with short or long-term deficits requiring rehabilitation or support.

Admissions do not necessarily equate to individuals because some people are admitted more than once. Approximately $85 \%$ of all admissions are individual patients. Other people also die before admission so are not included (this particularly applies to stroke patients).

Many of those admitted each year will be left with no lasting cognitive, physical, or behavioural deficits as a result of their injuries. Others will not be so lucky and will face an arduous battle to rebuild their lives and relearn lost skills most of us take for granted, including walking and talking. However, even those who make good recoveries are still likely to require some short-term support and information.

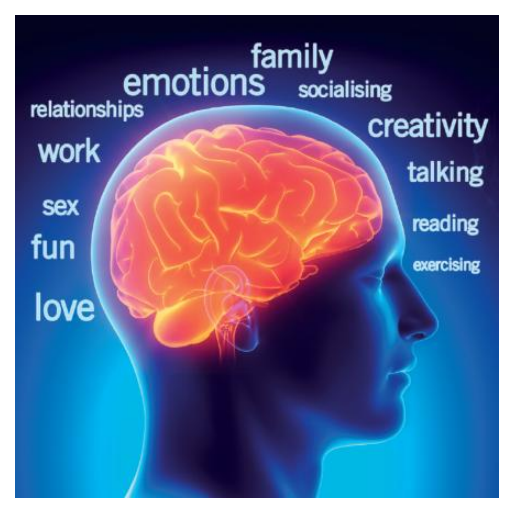

Prevalence estimates are notoriously problematic due to variation in injury severity and unpredictability of the level of disability people experience. However, it is important to note that the majority of people admitted with ABI survive. That means, as time goes on, more and more people are living with the effects of brain injury.

There have been more than three million admissions in the UK since 2005-06 and more than four million in England, Northern Ireland and Wales since 2000-01. As a significant number of these people will require ongoing support, these figures represent an ever increasing health problem.

In addition to the people represented by these admission statistics, people often report to Headway that their brain injury has simply never been diagnosed. Many people slip through the net and are forced to live with the effects of brain injury 


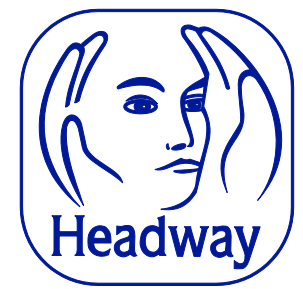

the brain injury association

without explanation, understanding or support. Also, previous research has suggested that a significant number of people with traumatic brain injury are not coded as such on admission, meaning they are not included in these statistics.

\section{Why have you released these statistics?}

The statistics presented in this report offer the most reliable data available to show the increasing number of people sustaining injuries to the brain each year and highlight the need for these people to be adequately supported.

This is the first time a picture of incidence rates for all $A B I$ in the UK has been published. This study builds on a report by Professor Alan Tennant that examined head injury incidence in England over two years, whereas Headway's current research has analysed all $\mathrm{ABI}$ across the entire UK over a 14 year period since the start of the century.

Professor Tennant's 2005 study fed into the National Service Framework for Longterm (Neurological) Conditions and he is widely regarded as the leading brain injury epidemiology expert in this country. As such, Headway is extremely grateful for his support of this project.

Headway hopes that by collating and releasing this data, more people will be aware not only of how many people each year are affected by brain injury, but also the array of conditions and causes of acquired brain injury.

The vast numbers presented here should also serve as a reminder of the importance of support services for those who are left with short or long-term problems as a result of their injuries.

Since 2005-6, the number of people admitted to hospital for an $A B I$ in the UK has risen by $10 \%$. This concerning statistic suggests an increased need for support services such as those provided by Headway.

Over the past five years in particular, Headway has seen a dramatic increase in demand for its services on a national and local level. Calls to the charity's UK-wide nurse-led helpline increased by $60 \%$ between 2010 and 2014, with approximately $70 \%$ of the enquiries received coming from people directly affected by brain injury.

On a local level, Headway groups and branches are also experiencing a increase in demand for support - either rehabilitative or social. Many are struggling to meet this demand against a backdrop of reduced funding, as demonstrated by the charity's 2014 study: A ticking time bomb: The false economy of cuts to brain injury services ${ }^{1}$.

\footnotetext{
${ }^{1}$ www.headway.org.uk/research/a-ticking-time-bomb-the-false-economy-of-cuts-to-brain-injury-services.aspx
} 
This study found that:

- $57 \%$ of Headway groups believe changes to local authority support have already had a direct impact on their ability to provide support services;

- $85 \%$ of Headway groups are concerned about their long-term survival;

- $89 \%$ of Headway groups have been forced to use reserves or additional charity funds to maintain vital their services.

With these new hospital admission statistics suggesting an increasing number of people are sustaining ABIs each year, a reduction in resources being directed to charities supporting those affected is of even greater concern.

\section{What are the reasons behind the increases?}

Further analysis of these statistics is required in order to identify possible reasons for trends and causes that could aid prevention campaigns, and improve acute care

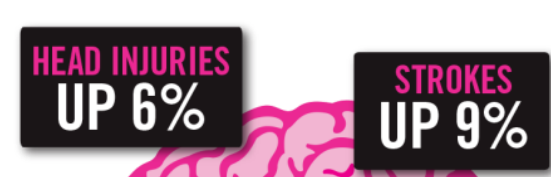

provision and community-based rehabilitation services in the future.

What we can take from these data, however, is that more and more people are being admitted to hospital each year with ABI-related diagnoses. The vast ALL ABIS (a) $(106) 10$ IP $10 \%$ majority of these people survive, meaning more and more people each year are in need of help and support as SINCE 2005-6 they adjust to a life with brain injury.

\section{Conclusion}

It is vital that a true picture of the number of people affected by brain injury each year is captured in order to ensure appropriate resources are diverted to meet the short and long-term support needs of this significant population.

More research is required to understand the reasons behind why the number of $\mathrm{ABI}$ related diagnoses has increased. But the shocking statistics presented here clearly demonstrate that brain injury incidence rates are rising - and as a result more people are requiring support to help them cope with their life-changing brain injuries.

Headway hopes that this information will increase the public's awareness of the wide range of conditions and causes of acquired brain injury, enable people to see that brain injury is more common that most realise, and emphasise the need for national and local brain injury services to be given the resources they need in order to help those affected. 


\section{Data tables}

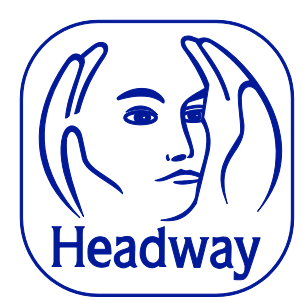

the brain injury association

\section{Chart 1: All ABI: Scotland, Northern Ireland, Wales and England}

\begin{tabular}{|l|r|r|r|r|r|r|r|}
\hline Year & \multicolumn{1}{|l|}{ Male } & Rate $^{*}$ & Female & \multicolumn{1}{|l|}{ Rate $^{*}$} & Unknown & \multicolumn{1}{l|}{ Total } & Rate $^{*}$ \\
\hline $\mathbf{2 0 0 5 - 0 6}$ & 184,776 & 625 & 132,370 & 429 & 37 & $\mathbf{3 1 7 , 1 8 3}$ & 525 \\
\hline $\mathbf{2 0 0 6 - 0 7}$ & 188,755 & 634 & 133,293 & 429 & 37 & $\mathbf{3 2 2 , 0 8 5}$ & 530 \\
\hline $\mathbf{2 0 0 7 - 0 8}$ & 188,285 & 627 & 134,416 & 430 & 32 & $\mathbf{3 2 2 , 7 3 3}$ & 526 \\
\hline $\mathbf{2 0 0 8 - 0 9}$ & 191,368 & 632 & 138,646 & 440 & 31 & $\mathbf{3 3 0 , 0 4 4}$ & 534 \\
\hline $\mathbf{2 0 0 9 - 1 0}$ & 198,483 & 653 & 147,257 & 468 & 45 & $\mathbf{3 4 5 , 7 8 5}$ & 559 \\
\hline $\mathbf{2 0 1 0 - 1 1}$ & 199,652 & 651 & 148,726 & 470 & 30 & $\mathbf{3 4 8 , 4 0 8}$ & 559 \\
\hline $\mathbf{2 0 1 1 - 1 2}$ & 200,650 & 645 & 151,289 & 470 & 15 & $\mathbf{3 5 1 , 9 5 4}$ & 556 \\
\hline $\mathbf{2 0 1 2 - 1 3}$ & 192,009 & 613 & 150,649 & 465 & 15 & $\mathbf{3 4 2 , 6 7 3}$ & 538 \\
\hline $\mathbf{2 0 1 3 - 1 4}$ & 194,734 & 618 & 154,169 & 473 & 31 & $\mathbf{3 4 8 , 9 3 4}$ & 544 \\
\hline $\begin{array}{l}\text { Change since } \\
\mathbf{2 0 0 5 - 0 6} \%\end{array}$ & 5 & -1 & 16 & 10 & -16 & $\mathbf{1 0}$ & 4 \\
\hline
\end{tabular}

${ }^{*}$ Rate is per 100,000 population.

* Data for Scotland are currently available from 2005-6. Therefore, data for the entire UK is presented from that time. Data for England, Northern Ireland and Wales are available from 2000/01, so combined data for those countries are presented separately (charts 4-6).

Chart 2: Head injury: Scotland, Northern Ireland, Wales and England

\begin{tabular}{|l|r|r|r|r|r|r|r|}
\hline Year & \multicolumn{1}{|l|}{ Male } & \multicolumn{1}{|c|}{ Rate $^{*}$} & \multicolumn{1}{l}{ Female } & Rate $^{*}$ & Unknown $^{\text {Total }}$ & Rate $^{*}$ \\
\hline $\mathbf{2 0 0 5 - 0 6}$ & 104,286 & 353 & 49,756 & 165 & 25 & $\mathbf{1 5 4 , 0 6 7}$ & 255 \\
\hline $\mathbf{2 0 0 6 - 0 7}$ & 107,773 & 362 & 51,041 & 169 & 22 & $\mathbf{1 5 8 , 8 3 5}$ & 261 \\
\hline $\mathbf{2 0 0 7 - 0 8}$ & 106,535 & 355 & 52,010 & 171 & 19 & $\mathbf{1 5 8 , 5 6 4}$ & 259 \\
\hline $\mathbf{2 0 0 8 - 0 9}$ & 106,816 & 353 & 53,813 & 176 & 23 & $\mathbf{1 6 0 , 6 5 2}$ & 260 \\
\hline $\mathbf{2 0 0 9 - 1 0}$ & 111,067 & 365 & 59,632 & 195 & 20 & $\mathbf{1 7 0 , 7 1 8}$ & 276 \\
\hline $\mathbf{2 0 1 0 - 1 1}$ & 108,756 & 354 & 59,767 & 194 & 16 & $\mathbf{1 6 8 , 5 3 9}$ & 270 \\
\hline $\mathbf{2 0 1 1 - 1 2}$ & 108,923 & 350 & 60,494 & 195 & 9 & $\mathbf{1 6 9 , 4 2 6}$ & 268 \\
\hline $\mathbf{2 0 1 2 - 1 3}$ & 99,008 & 316 & 58,503 & 187 & 11 & $\mathbf{1 5 7 , 5 2 2}$ & 247 \\
\hline $\mathbf{2 0 1 3 - 1 4}$ & 100,831 & 320 & 61,701 & 196 & 12 & $\mathbf{1 6 2 , 5 4 4}$ & 254 \\
\hline $\begin{array}{l}\text { Change since } \\
\mathbf{2 0 0 5 - 0 6} \%\end{array}$ & -3 & -9 & 24 & 19 & -52 & $\mathbf{6}$ & -1 \\
\hline
\end{tabular}

${ }^{*}$ Rate is per 100,000 population. 


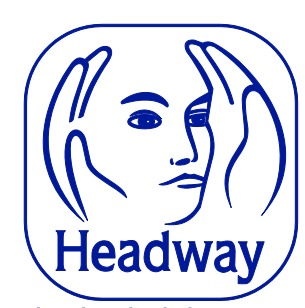

the brain injury association

Chart 3: Stroke: Scotland, Northern Ireland, Wales and England

\begin{tabular}{|c|c|c|c|c|c|c|c|}
\hline Year & Male & Rate* $^{*}$ & Female & Rate* $^{*}$ & Unknown & Total & Rate* \\
\hline 2005-06 & 57,598 & 195 & 62,488 & 202 & 12 & 120,098 & 199 \\
\hline 2006-07 & 56,681 & 190 & 60,246 & 194 & 12 & 116,939 & 192 \\
\hline 2007-08 & 56,608 & 189 & 59,919 & 191 & 10 & 116,537 & 190 \\
\hline 2008-09 & 59,192 & 195 & 61,793 & 196 & 8 & 120,993 & 196 \\
\hline 2009-10 & 61,315 & 202 & 63,960 & 203 & 17 & 125,292 & 202 \\
\hline 2010-11 & 63,531 & 207 & 64,730 & 204 & 12 & 128,273 & 206 \\
\hline 2011-12 & 64,369 & 207 & 65,422 & 203 & 6 & 129,797 & 205 \\
\hline 2012-13 & 65,369 & 209 & 66,101 & 204 & 3 & 131,473 & 206 \\
\hline 2013-14 & 65,315 & 207 & 65,232 & 200 & 4 & 130,551 & 204 \\
\hline $\begin{array}{l}\text { Change since } \\
2005-06 \%\end{array}$ & 13 & 6 & 4 & -1 & -67 & 9 & 2 \\
\hline
\end{tabular}

${ }^{*}$ Rate is per 100,000 population.

Chart 4: All ABI: Northern Ireland, Wales and England

\begin{tabular}{|c|c|c|c|c|c|c|c|}
\hline Year & Male & Rate $^{*}$ & Female & Rate* $^{*}$ & Unknown & Total & Rate* \\
\hline 2000-01 & 153,360 & 584 & 111,878 & 406 & 350 & 265,588 & 493 \\
\hline 2001-02 & 154,719 & 586 & 111,983 & 405 & 199 & 266,901 & 494 \\
\hline 2002-03 & 152,635 & 575 & 113,131 & 407 & 28 & 265,794 & 489 \\
\hline 2003-04 & 158,195 & 593 & 114,125 & 409 & 21 & 272,341 & 499 \\
\hline 2004-05 & 163,232 & 608 & 117,715 & 420 & 36 & 280,983 & 512 \\
\hline 2005-06 & 171,561 & 634 & 123,095 & 436 & 37 & 294,693 & 533 \\
\hline 2006-07 & 175,179 & 642 & 124,070 & 437 & 37 & 299,286 & 537 \\
\hline 2007-08 & 174,024 & 632 & 125,066 & 437 & 32 & 299,122 & 533 \\
\hline 2008-09 & 177,362 & 638 & 128,993 & 447 & 31 & 306,386 & 541 \\
\hline 2009-10 & 184,878 & 663 & 137,681 & 479 & 45 & 322,604 & 570 \\
\hline 2010-11 & 186,662 & 663 & 139,471 & 482 & 30 & 326,163 & 571 \\
\hline 2011-12 & 187,290 & 657 & 141,712 & 481 & 15 & 329,017 & 567 \\
\hline $2012-13$ & 179,512 & 625 & 141,229 & 476 & 15 & 320,756 & 549 \\
\hline 2013-14 & 182,766 & 631 & 144,920 & 486 & 31 & 327,717 & 558 \\
\hline $\begin{array}{l}\text { Change this } \\
\text { century } \%\end{array}$ & 19 & 8 & 30 & 20 & -91 & 23 & 13 \\
\hline
\end{tabular}

${ }^{*}$ Rate is per 100,000 population. 
Chart 5: Head injury: Northern Ireland, Wales and England

\begin{tabular}{|l|r|r|r|r|r|r|r|}
\hline Year & \multicolumn{1}{|l|}{ Male } & \multicolumn{1}{|c|}{ Rate $^{*}$} & Female & Rate $^{*}$ & Unknown & \multicolumn{1}{l}{ Total } & Rate $^{*}$ \\
\hline $\mathbf{2 0 0 0 - 0 1}$ & 79,358 & 302 & 35,569 & 129 & 291 & $\mathbf{1 1 5 , 2 1 8}$ & 214 \\
\hline $\mathbf{2 0 0 1 - 0 2}$ & 80,954 & 307 & 35,751 & 129 & 135 & $\mathbf{1 1 6 , 8 4 0}$ & 216 \\
\hline $\mathbf{2 0 0 2 - 0 3}$ & 79,309 & 299 & 35,528 & 128 & 21 & $\mathbf{1 1 4 , 8 5 8}$ & 212 \\
\hline $\mathbf{2 0 0 3 - 0 4}$ & 84,857 & 318 & 37,854 & 136 & 15 & $\mathbf{1 2 2 , 7 2 6}$ & 225 \\
\hline $\mathbf{2 0 0 4 - 0 5}$ & 89,680 & 334 & 41,653 & 149 & 24 & $\mathbf{1 3 1 , 3 5 7}$ & 239 \\
\hline $\mathbf{2 0 0 5 - 0 6}$ & 95,495 & 353 & 45,522 & 161 & 25 & $\mathbf{1 4 1 , 0 4 2}$ & 255 \\
\hline $\mathbf{2 0 0 6 - 0 7}$ & 98,636 & 361 & 46,723 & 164 & 22 & $\mathbf{1 4 5 , 3 8 1}$ & 261 \\
\hline $\mathbf{2 0 0 7 - 0 8}$ & 96,769 & 351 & 47,442 & 166 & 19 & $\mathbf{1 4 4 , 2 3 0}$ & 257 \\
\hline $\mathbf{2 0 0 8 - 0 9}$ & 97,428 & 351 & 49,250 & 171 & 23 & $\mathbf{1 4 6 , 7 0 1}$ & 259 \\
\hline $\mathbf{2 0 0 9 - 1 0}$ & 102,110 & 366 & 55,118 & 192 & 20 & $\mathbf{1 5 7 , 2 4 8}$ & 278 \\
\hline $\mathbf{2 0 1 0 - 1 1}$ & 100,290 & 356 & 55,470 & 192 & 16 & $\mathbf{1 5 5 , 7 7 6}$ & 273 \\
\hline $\mathbf{2 0 1 1 - 1 2}$ & 100,162 & 351 & 55,825 & 189 & 9 & $\mathbf{1 5 5 , 9 9 6}$ & 269 \\
\hline $\mathbf{2 0 1 2 - 1 3}$ & 91,208 & 317 & 53,980 & 182 & 11 & $\mathbf{1 4 5 , \mathbf { 1 9 9 }}$ & 249 \\
\hline $\mathbf{2 0 1 3 - 1 4}$ & 93,403 & 323 & 57,191 & 192 & 12 & $\mathbf{1 5 0 , 6 0 6}$ & 256 \\
\hline $\begin{array}{l}\text { Change this } \\
\text { century \% }\end{array}$ & 18 & 7 & 61 & 49 & -96 & $\mathbf{3 1}$ & 20 \\
\hline
\end{tabular}

${ }^{*}$ Rate is per 100,000 population.

Chart 6: Stroke: Northern Ireland, Wales and England

\begin{tabular}{|c|c|c|c|c|c|c|c|}
\hline Year & Male & Rate* & Female & Rate $^{*}$ & Unknown & Total & Rate* \\
\hline 2000-01 & 51,222 & 195 & 56,751 & 206 & 57 & 108,030 & 201 \\
\hline 2001-02 & 51,920 & 197 & 56,912 & 206 & 62 & 108,894 & 201 \\
\hline 2002-03 & 53,187 & 200 & 58,993 & 212 & 7 & 112,187 & 207 \\
\hline 2003-04 & 52,769 & 198 & 57,587 & 207 & 6 & 110,362 & 202 \\
\hline 2004-05 & 52,423 & 195 & 57,589 & 206 & 8 & 110,020 & 201 \\
\hline 2005-06 & 53,174 & 196 & 57,447 & 204 & 12 & 110,633 & 200 \\
\hline 2006-07 & 52,242 & 191 & 55,340 & 195 & 12 & 107,594 & 193 \\
\hline 2007-08 & 52,113 & 189 & 55,137 & 193 & 10 & 107,260 & 191 \\
\hline 2008-09 & 54,575 & 196 & 56,703 & 197 & 8 & 111,286 & 197 \\
\hline 2009-10 & 56,667 & 203 & 58,897 & 205 & 17 & 115,581 & 204 \\
\hline 2010-11 & 59,007 & 210 & 59,772 & 206 & 12 & 118,791 & 208 \\
\hline 2011-12 & 59,769 & 210 & 60,515 & 205 & 6 & 120,290 & 207 \\
\hline 2012-13 & 60,672 & 211 & 61,204 & 206 & 3 & 121,879 & 209 \\
\hline 2013-14 & 60,775 & 210 & 60,493 & 203 & 4 & 121,272 & 206 \\
\hline $\begin{array}{l}\text { Change this } \\
\text { century } \%\end{array}$ & 19 & 8 & 7 & -2 & -93 & 12 & 3 \\
\hline
\end{tabular}

${ }^{*}$ Rate is per 100,000 population. 


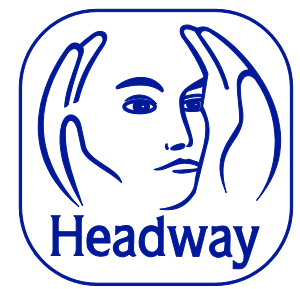

the brain injury association

\section{Further information}

- For detailed regional and national data for all $\mathrm{ABI}$-related conditions, and more information on the methodology of the research, visit www.headway.org.uk/brain-injury-stats.aspx or click here.

- For further information about brain injury and Headway services across the UK, visit www.headway.org.uk.

- If you have been affected by brain injury and would like support, or if you have a question about brain injury or services available, contact the charity's helpline on 08088002244 or helpline@headway.org.uk.

- If you have any queries about the statistics, please contact Richard Morris, Publications and Research Manager, on publications@headway.org.uk.

- Any media enquiries should be directed to Luke Griggs, Director of Communications, on directorofcomms@headway.org.uk or Rachel Smith, Press Officer, on press.officer@headway.org.uk or 01159241906. 